Танюкевич Вадим Викторович, профессор кафедры лесоводства и лесных мелиораций Новочеркасского инженерно-мелиоративного института им. А.К. Кортунова ( РФ, г. Новочеркасск, ул. Пушкинская, 111). vadimlug79@mail.ru

Баканов Илья Александрович, аспирант, студент Новочеркасского инженерно-мелиоративного института им. А.К. Кортунова ( РФ, г. Новочеркасск, ул. Пушкинская, 111). Bakanov61rus@yandex.ru

\title{
THE INFLUENCE OF GROWTH STIMULATORS ON THE YIELD AND ECONOMIC EFFICIENCY OF ONIONS IN THE CONDITIONS OF THE ARID ZONE OF THE ASTRAKHAN REGION
}

DOI: 10.32786/2071-9485-2021-03-11

\author{
N.V. Tyutyuma, A.N. Bondarenko, D.V. Chernik \\ Federal State Budget Scientific Institution «Precaspian Agrarian Federal Scientific Center \\ of the Russian Academy of Sciences», Astrakhan region
}

Received 01.06.2021

Submitted 26.07.2021

\begin{abstract}
The research was carried out in the framework of research in 2018-2021. "Improve zonal agricultural technologies for crop cultivation in order to effectively use the natural resource potential of agricultural landscapes of the Northern Caspian region " Topic № 0722-2019-0016
\end{abstract}

\begin{abstract}
Summary
The results of growing canteen beets under conditions of light chestnut soil on drip irrigation are presented. Promising options have been identified that contribute to the formation of a high yield of the studied crop.
\end{abstract}

\begin{abstract}
Introduction. In the zone of the North-Western Caspian Sea, the cultivation of onions is considered very expensive. The main share of investments falls on drip irrigation of this crop. A small supply of nutrients in light chestnut saline soils is replenished by the introduction of mineral fertilizers and the use of preparations that stimulate the development of onions. Object. Various varieties of onions of domestic selection. Materials and methods. The object of the study was various varieties and hybrids of onion adapted to the soil and climatic conditions of the North-Western Caspian Sea. The tests were carried out on experimental landuse plots of the Federal State Budget Scientific Institution «Caspian Agrarian Federal Scientific Center of the Russian Academy of Sciences» during 2019-2020. Results and discussion. According to the results obtained in the course of research, it is necessary to highlight the following: the difference in yield and economic efficiency is due to the influence of drugs that affect the varieties and hybrids under study. Such, for example, is the synthetic drug Novosil, which had a significantly positive effect on all varieties and hybrids. The Bayram F1 hybrid had a fairly high biological yield of 127.2 t/ha in this variant. According to the results of the two years of study, the commercial yield was $117.2 \mathrm{t} /$ ha, and the marketability was $92 \%$. The profitability of production was equal to $245 \%$. In the Kristina variety, the biological yield was slightly lower than $122.6 \mathrm{t} /$ ha, while the commercial yield was $110.5 \mathrm{t} /$ ha, the marketability was $90 \%$. The commercial yield of the Gordion variety was $105.3 \mathrm{t} / \mathrm{ha}$, similar to the variant with the use of the drug Novosil, the marketability was $89.5 \%$. According to the results of the conducted studies, it was found that the use of growth-stimulating drugs significantly increased the economic efficiency of the cultivation of the studied varieties and the onion hybrid.
\end{abstract}

Key words: hybrid, variety, onion, growth-stimulating drugs, yield, profitability.

Citation. Tyutyuma N.V., Bondarenko A. N., Chernik D. V. The influence of growth stimulators on the yield and economic efficiency of onions in the conditions of the arid zone of the Astrakhan region. Proc. of the Lower Volga Agro-University Comp. 2021. 3(63). 115-122 (in Russian). DOI: 10.32786/2071-9485-2021-03-11.

Author's contribution. All authors of this study were directly involved in the planning, execution, or analysis of this study. All the authors of this article have read and approved the final version presented.

Conflict of interest. The authors declare that there is no conflict of interest. 


\section{ВЛИЯНИЕ СТИМУЛЯТОРОВ РОСТА НА УРОЖАЙНОСТЬ И ЭКОНОМИЧЕСКУЮ ЭФФЕКТИВНОСТЬ ЛУКА РЕПЧАТОГО В УСЛОВИЯХ АРИДНОЙ ЗОНЫ АСТРАХАНСКОЙ ОБЛАСТИ}

Н. В. Тютюма, доктор сельскохозяйственных наук, профессор РАН,

А. Н. Бондаренко, доктор сельскохозяйственных наук Д. В. Черник, младший научный сотрудник

ФГБНУ Прикаспийский аграрный федеральный научный центр РАН, Астраханская область, Черноярский район, село Солёное Займище

Дата поступления в редакцию 01.06. 2021

Дата принятия к печати 26.07.2021

\section{Исследования проведены в рамках тематики НИР 2018-2021 г2. «Усовершенствовать зональные агротехнологии возделывания сельскохозяйственных культур с целью эффективного использования природно-ресурсного потенциала агроландиафтов Северного Прикаспия» Тема № 0722-2019-0016}

Актуальность. В зоне Северо-Западного Прикаспия возделывание лука репчатого считается очень дорогостоящим. Основная доля вложений приходится на капельное орошение данной культуры. Малый запас питательных веществ в светло-каштановых солонцеватых почвах восполняется за счет внесения минеральных удобрений и использования препаратов, стимулирующих развитие лука репчатого. Объект. Различные сорта лука репчатого отечественной селекции. Материалы и методы. Объектом исследования являлись различные сорта и гибрид лука репчатого, адаптированные к почвенно-климатическим условиям Северо-Западного Прикаспия. Испытания проводились на опытных участках землепользования ФГБНУ «ПАФНЦ РАН» в течение 2019-2020 гг. Результаты и обсуждение. По результатам, полученным в ходе исследований, необходимо отметить следующее: различие в урожайности и экономической эффективности обусловлено влиянием препаратов, оказывающих влияние на сорта и гибрид, находящихся в изучении. Таким, к примеру, является синтетический препарат Новосил, который оказал существенное положительное влияние на все сорта и гибрид. Достаточно высокие показатели по биологической урожайности 127,2 т/га были у гибрида Байрам F1 на данном варианте. Товарная урожайность составляла по итогам двух лет изучения 117,2 т/га, товарность 92 \%. Рентабельность производства была равна 245 \%. У сорта Кристина биологическая урожайность была чуть ниже 122,6 т/га, при этом товарная урожайность составляла 110,5 т/га, товарность - $90 \%$. Товарная урожайность у сорта Гордион составила 105,3 т/га аналогично по варианту с применением препарата Новосил, товарность - 89,5 \%. По итогам проведенных исследований было установлено, что применение ростостимулирующих препаратов значительно повысило экономическую эффективность возделывания изучаемых сортов и гибрида лука репчатого.

Ключевые слова: гибриды лука репчатого, сорта лука репчатого, ростостимулируюшие препарать, урожайность лука репчатого.

Цитирование. Тютюма Н. В., Бондаренко А. Н., Черник Д. В. Влияние стимуляторов роста на урожайность и экономическую эффективность лука репчатого в условиях аридной зоны Астраханской области. Известия НВ АУК. 2021. 3(63). 115-122. DOI: 10.32786/2071-9485-2021-03-11.

Авторский вклад. Все авторы настоящего исследования принимали непосредственное участие в планировании, выполнении или анализе данного исследования. Все авторы настоящей статьи ознакомились и одобрили представленный окончательный вариант.

Конфликт интересов. Авторы заявляют об отсутствии конфликта интересов.

Введение. Лук репчатый (Állium cépa) - широко распространенная овощная культура [4-11]. 


\section{***** H3BECTKЯ ***** \\ НИЖНЕВОАЖСКОГО АГРОУНИВЕРСИТЕТСКОГО КОМПАЕКСА: НАУКА И ВЫСШЕЕ ПРОФЕССИОНААЬНОЕ ОБРАЗОВАНИЕ}

Возделывание культуры лука репчатого в условиях аридной зоны Астраханской области является весьма перспективным направлением в отрасли растениеводства [1]. Однако климатические особенности данного региона, обусловленные малым количеством осадков и высокими температурами, в сочетании с низким процентом гумуса, требуют при выращивании данной культуры особого подхода.

Применение капельного способа полива с добавлением различных препаратов через капельную ленту позволяет полноценно восполнять недостающие микроэлементы для растений лука репчатого в течение всего периода вегетации [3].

В настоящее время весьма актуальным становится использование при возделывании лука репчатого ряда современных ростостимулирующих препаратов по листу в виде подкормок [2].

Целью исследования являлось изучение влияния ростостимулирующих препаратов нового поколения на растения лука репчатого в период вегетации, которые были направлены на повышение урожайности в зоне светло-каштановых солонцеватых почв Астраханской области.

В задачи исследований входило:

1. Определить более перспективные сорта и гибриды лука репчатого, обладающие более высоким потенциалом биологической и товарной урожайности на фоне применения минеральных подкормок и листовых обработок ростостимулирующими препаратами.

2. Рассмотреть действие ростостимулирующих препаратов и минеральных подкормок на показатели и элементы структуры урожая лука репчатого.

3. Определить экономическую эффективность при возделывании сортов и гибрида лука репчатого в зависимости от вариантов внекорневых подкормок.

Научная новизна. Впервые в аридной зоне Астраханской области проводится испытание по использованию внекорневых обработок современными ростостимулирующими препаратами и минеральными подкормками при возделывании сортов и гибридов лука репчатого на капельном орошении.

Материалы и методы. В ходе НИР методом расщепленных делянок был заложен двухфакторный полевой опыт по культуре «лук репчатый», повторность опыта трехкратная. Размещение делянок - систематическое [3].

В двухфакторном полевом опыте Фактор А - среднеспелые сорта и гибриды лука репчатого: Кристина, Гордион, Сима, Байрам F1.

Фактор В - антистрессовый агрохимикат с высоким содержанием аминокислот Аминофол Плюс (стимулирует метаболизм и усвоение питательных веществ, существенно повышает урожайность), ростостимулятор Новосил (способствует увеличению урожайности до $25 \%$ ), комплексное минеральное удобрение для листовой подкормки Здравень турбо универсальный ускоряет развитие растений.

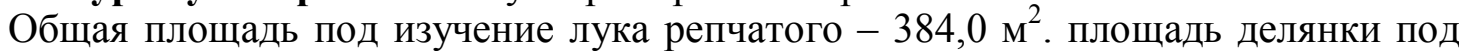
сорт - 96,0 м², площадь делянки под вариантами - 32,0 м². Площадь учетной делянки -

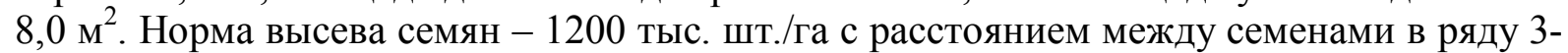
4 см. Схема посева (многорядная) - 0,10 м $x$ 0,08 м (отступ от капельной ленты 0,10 м с расстоянием между рядками 0,08 м) на гряде шириной 0,7 м. Технологическая колея 0,7 м. Способ посева - овощная сеялка точного высева Schmotzer с одновременной раскладкой капельных лент, способ полива - система капельного орошения.

На протяжении вегетации вносилось комплексное сложное минеральное удобрение азофоска $\mathrm{N}_{16} \mathrm{P}_{16} \mathrm{~K}_{16}$ из расчета $\mathrm{N}_{60} \mathrm{P}_{60} \mathrm{~K}_{60}$.под основную обработку почв.

Дополнительно в период вегетации вносилась с поливной водой аммиачная селитра дробно 4 раза за вегетацию - $\mathrm{N}_{30}$. Общее содержание внесенных минеральных удобрений составило $\mathrm{N}_{180} \mathrm{P}_{60} \mathrm{~K}_{60}$. 
1. Контроль - без обработки.

Варианты опыта:

2. Аминофол Плюс - 1-я подкормка в фазе 3-5 листьев, 2-я и 3-я подкормки с интервалом 10-14 сут. после последней подкормки. Норма расхода препарата - 1,0 л/га. Расход рабочего раствора - 200,0 л/га, согласно нормам от товаропроизводителя.

3. Новосил - 1-я в фазе образования 4 листа, 2-я - через 15 сут. после первого опрыскивания. Норма расхода препарата - 100 мл/га. Расход рабочего раствора - 300 л/га, согласно нормам от товаропроизводителя.

4. Здравень турбо - обработка в фазе 3-4 настоящих листьев, 2-я - через 2-3 недели после первой, 3-я - в период формирования урожая. Расход препарата - 10 г/10 л воды. Расход рабочего раствора - 250 л/га, согласно нормам от товаропроизводителя.

Для выполнения поставленных задач проводились полевые учеты, наблюдения и измерения с использованием «Методики полевого опыта» Доспехова Б. А. «Методики опытного дела в растениеводстве» Никитенко Г. Ф. 1982 г., «Методики опытного дела в овощеводстве и бахчеводстве» под редакцией Белика В. Ф., Литвинова С. С., «Методики Государственного сортоиспытания сельскохозяйственных культур» 2015 г., а также согласно «Методическому руководству по проведению регистрационных испытаний агрохимикатов в сельском хозяйстве» 2018 г.

Результаты и обсуждение. Анализируя данные таблицы 1, необходимо констатировать следующее: самыми урожайными в изучении по всем показателям стали гибрид Байрам F1 и сорт Кристина. Средняя масса луковицы с делянки с применением препарата Новосил у гибрида Байрам F1 составила 182,7 г, а у сорта Кристина - 182,0 г. Биологическая урожайность у гибрида Байрам F1 составила 127,2 т/га, у сорта Кристина - 122,6 т/га. Товарная урожайность у гибрида Байрам F1 была равна в среднем за два года изучения 117,2 т/га, у сорта Кристина - 110,5 т/га. При этом товарность у гибрида Байрам F1 - 92,0 \%, сорт Кристина - 90,0 \%.

Проведенный анализ экономической эффективности лука репчатого (таблица 2) позволяет выделить следующее: гибрид Байрам F1 отличился от сортов, представленных в изучении, высокими показателями как чистого дохода, так и рентабельности производства.

Так, на контрольном варианте у гибрида Байрам F1 урожайность в среднем за два года изучения составила всего 75,1 т/га при общих затратах на производство 337,8 тыс./p. Себестоимость 1 тонны продукции была равна 4,5 p./т, рентабельность составила $122 \%$. Экономическая эффективность $-2,5$ p./p. вложенных затрат.

Самые высокие показатели урожайности - 117,2 т/га - были получены у гибрида Байрам F1 с применением синтетического препарата Новосил. При этом себестоимость товарной продукции составляла 2,9 р./т, рентабельность производства -246 \%. Экономическая эффективность $-3,8$ p./p. вложенных затрат.

Необходимо отметить следующее: использование препарата Здравень Турбо на всех изучаемых сортах и гибридах не привело к существенной прибавке урожая относительно других вариантов, находящихся в изучении. При этом рентабельность производства находилась в диапазоне $114 \ldots .173$ \% (таблица 2).

Выводы. Результаты, полученные в исследовании, позволяют рекомендовать синтетический препарат Новосил в качестве внекорневой подкормки при возделывании лука репчатого Байрам F1 и Кристина в крестьянско-фермерских хозяйствах на территории аридной зоны Астраханской области. Чистый доход от использования данного препарата составил по итогам двух лет изучения 834,0-767,0 р./га, рентабельность производства $-227-247 \%$. 


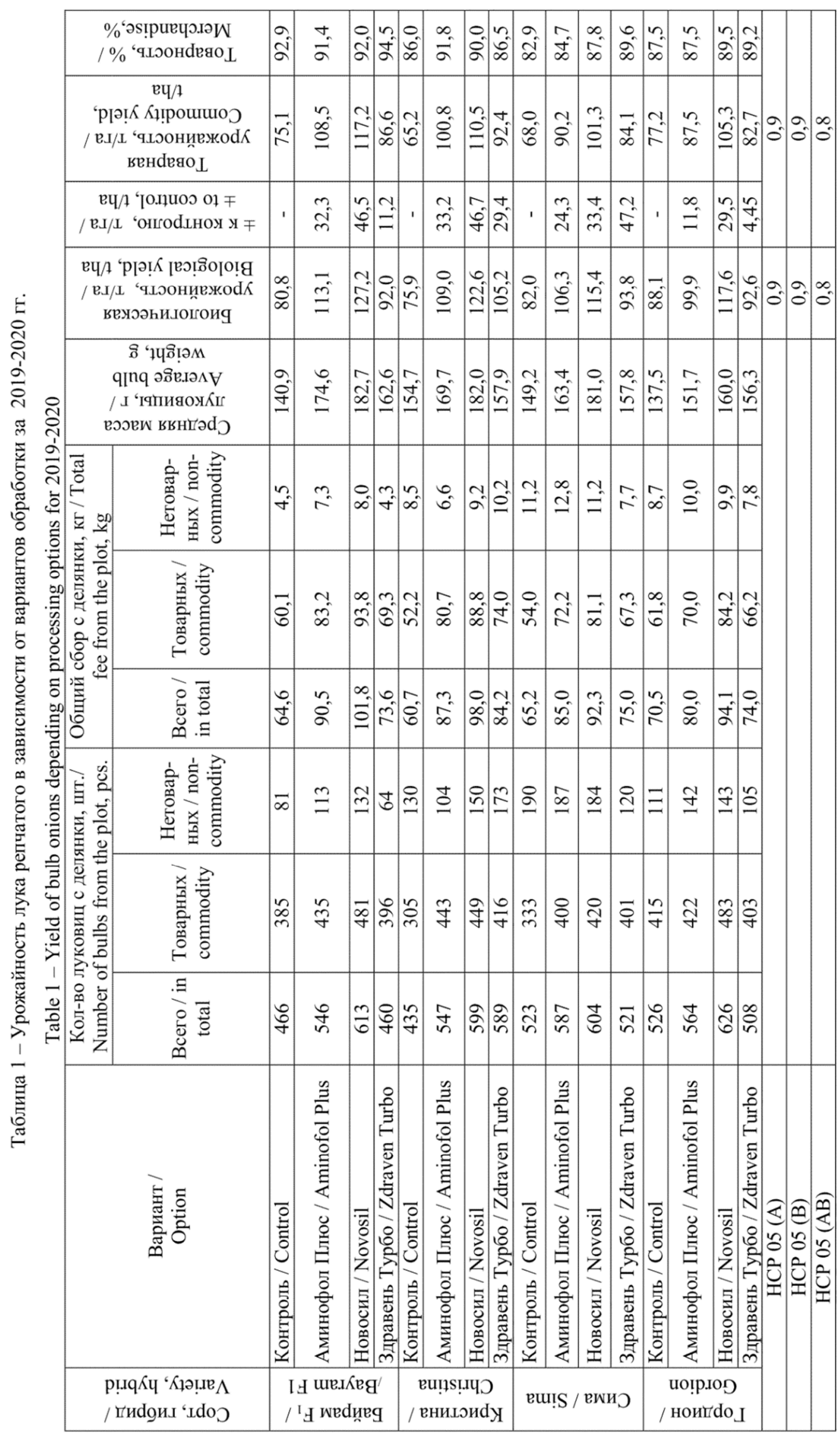


***** НЗВЕСТИЯ *****

НИЖНЕВОАЖСКОГО АГРОУНИВЕРСИТЕТСКОГО КОМПАЕКСА:

НАУКА И ВЫСШЕЕ ПРОФЕССИОНААЬНОЕ ОБРАЗОВАНИЕ

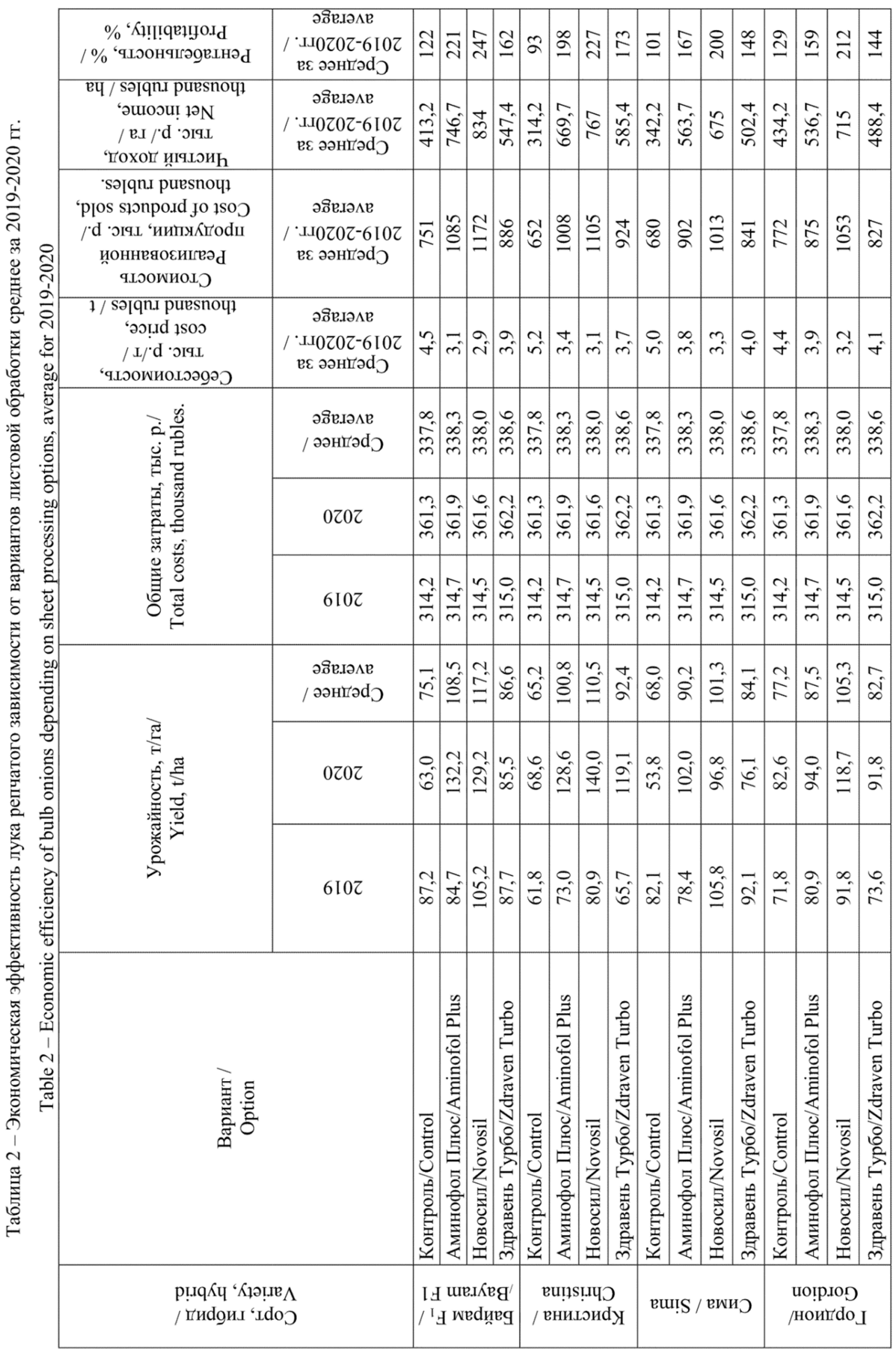




\section{Библиографический список}

1. Водообеспеченность - определяющий фактор эффективного развития лука репчатого / Н. И. Матвеева [и др.] //Аграрный научный журнал. 2019. № 11. С. 18-22.

2. Действие удобрений и регуляторов роста на урожайность и качество гибридов лука репчатого, выращенных в однолетней культуре при капельном орошении / В. А. Борисов [и др.] // Научно практический журнал. Овощи России. 2018. № 4. С.89-93.

3. Эффективные элементы возделывания репчатого лука при капельном орошении / $\mathrm{H}$. Ю. Петров [и др.] // Известия Нижневолжского агроуниверситетского комплекса: наука и высшее профессиональное образование. 2018. № 1 (49). С. 51-58.

4. Abdelsattar Abdelkhalik Regulated Deficit Irrigation as a Water-Saving Strategy for Onion // Cultivation in Mediterranean Conditions. 2019. P. 67.

5. Ansari N. A., Chamran S. C. Onion cultivation and production in Iran. Middle Eastern and Russian // J. of Plant Science and Biotechnology. 2019. Vol. 1. № 2. P. 23-38.

6. Ardell D. H. Nitrogen Effects on Onion Yield Under Drip and Furrow Irrigation // Agronomy Journal. 2008. V. 100. I. 4. P. 1062-1069.

7. Gupta R. C., Gupta R. P. Effect of integrated disease management packages on diseases incidence and bulb yield of onion (Allium cepa L.) // SAARC J. Agri. 2013. Vol. 11. P. 49-59.

8. Hanci F. A. Comprehensive overview of onion production: Worldwide and Turkey // IOSR J. of Agriculture and Veterinary Science (IOSR-JAVS). 2018. Vol. 11. P. 17-27.

9. Jiffinvir S. Khosa A Guide for the Cultivation of Onion under Controlled Environment Conditions // HortScience: a publication of the American Society for Horticultural Science. 2018. V. 53(12). P. 1746-1749.

10. Khosa Jiffinvir A Guide for the Cultivation of Onion under Controlled Environment Conditions // Hort Science. 53. Acta agronomica sinica. 2018. P. 1746-1749.

11. Khvan O. V., Podkovyrov I. Y. Definition of the criteria influencing on cultivation conditions of onions // Russian Journal of Agricultural and Socio-Economic Science. 2016. P. 15-20.

Conclusions. The results obtained in the study make it possible to recommend the synthetic preparation Novosil as an extracorporeal feed when cultivating onions of Bayram F1 and Kristina onions in peasant farms in the arid zone of the Astrakhan region. According to the results of two years of study, net income from the use of this drug amounted to 834.0$767.0 \mathrm{p} / \mathrm{ha}$, profitability of production $-227-247 \%$.

\section{References}

1. Vodoobespechennost' - opredelyayuschij faktor jeffektivnogo razvitiya luka repchatogo / N. I. Matveeva [i dr.] //Agrarnyj nauchnyj zhurnal. 2019. № 11. P. 18-22.

2. Dejstvie udobrenij i regulyatorov rosta na urozhajnost' i kachestvo gibridov luka repchatogo, vyraschennyh v odnoletnej kul'ture pri kapel'nom oroshenii / V. A. Borisov [i dr.] // Nauchno prakticheskij zhurnal. Ovoschi Rossii. 2018. № 4. P.89-93.

3. Jeffektivnye jelementy vozdelyvaniya repchatogo luka pri kapel'nom oroshenii / N. Yu. Petrov [i dr.] // Izvestiya nizhnevolzhskogo agrouniversitetskogo kompleksa: nauka i vysshee professional'noe obrazovanie. 2018. № 1 (49). P. 51-58.

4. Abdelsattar Abdelkhalik Regulated Deficit Irrigation as a Water-Saving Strategy for Onion // Cultivation in Mediterranean Conditions. 2019. P. 67.

5. Ansari N. A., Chamran S. C. Onion cultivation and production in Iran. Middle Eastern and Russian // J. of Plant Science and Biotechnology. 2019. Vol. 1. № 2. P. 23-38.

6. Ardell D. H. Nitrogen Effects on Onion Yield Under Drip and Furrow Irrigation // Agronomy Journal. 2008. V. 100. I. 4. P. 1062-1069.

7. Gupta R. C., Gupta R. P. Effect of integrated disease management packages on diseases incidence and bulb yield of onion (Allium cepa L.) // SAARC J. Agri. 2013. Vol. 11. P. 49-59.

8. Hanci F. A. Comprehensive overview of onion production: Worldwide and Turkey // IOSR J. of Agriculture and Veterinary Science (IOSR-JAVS). 2018. Vol. 11. P. 17-27.

9. Jiffinvir S. Khosa A Guide for the Cultivation of Onion under Controlled Environment Conditions // HortScience: a publication of the American Society for Horticultural Science. 2018. V. 53(12). P. 1746-1749. 


\title{
***** H3BECTYЯ ***** \\ НИЖНЕВОАЖСКОГО АГРОУНИВЕРСИТЕТСКОГО КОМПАЕКСА: \\ НАУКА И ВЫСШЕЕ ПРОФЕССИОНААЬНОЕ ОБРАЗОВАНИЕ
}

10. Khosa Jiffinvir A Guide for the Cultivation of Onion under Controlled Environment Conditions // Hort Science. 53. Acta agronomica sinica. 2018. P. 1746-1749.

11. Khvan O. V., Podkovyrov I. Y. Definition of the criteria influencing on cultivation conditions of onions // Russian Journal of Agricultural and Socio-Economic Science. 2016. P. 15-20.

\section{Authors information}

Tyutyuma Natalia Vladimirovna, Doctor of Agricultural Sciences, Professor of the Russian Academy of Sciences, Director Federal State Budget Scientific Institution «Caspian Agrarian Federal Scientific Center of the Russian Academy of Sciences», 416251. Astrakhan region, Chernoyarsky district, sq. - 1 Severny 8. E-mail. pniiaz@ mail.ru (ORSID ID № 0000-0001-6582-2628)

Bondarenko Anastasia Nikolaevna, Doctor of Agricultural Sciences, Head of the Department. laboratory of agricultural technologies of vegetable cultures.Federal State Budget Scientific Institution «Caspian Agrarian Federal Scientific Center of the Russian Academy of Sciences», 416251. Astrakhan region, Chernoyarsky district, sq. - 1 Severny 8. E-mail. pniiaz@ mail.ru. (ORSID ID № 0000-0003-4816-5667)

Chernik Dmitry Vladimirovich-M. Sc. of the laboratory of agrotechnologies of vegetable crops.Federal State Budget Scientific Institution «Caspian Agrarian Federal Scientific Center of the Russian Academy of Sciences», 416251. Astrakhan region, Chernoyarsky district, sq. - 1 Severny 8.

(ORCID ID № 0000-0002-0709-1844

\section{Информация об авторах}

Тютюма Наталья Владимировна, д.с.-х.н., профессор РАН, директор ФГБНУ «ПАФНЦ РАН». 416251. Астраханская область, Черноярский район, кв.-л Северный 8). E-mail. pniiaz@mail.ru (ORSID ID № 0000-0001-6582-2628)

Бондаренко Анастасия Николаевна, д.с.-х.н., зав. лабораторией агротехнологий овощных культур. ФГБНУ «ПАФНЦ РАН» (416251. Астраханская область, Черноярский район, кв.-л Северный 8). E-mail.pniiaz@ mail.ru. ORSID ID № 0000-0003-4816-5667

Черник Дмитрий Владимирович, м.н.с. лаборатории агротехнологий овощных культур. ФГБНУ «Прикаспийский аграрный федеральный научный центр Российской академии наук» (416251. Астраханская область, Черноярский район, кв.-л Северный 8).

ORCID ID № 0000-0002-0709-1844.

\section{MID-SEASON AND HIGHLY PRODUCTIVE AEROBIC RICE VARIETY STALINGRAD 1 FOR IRRIGATION BY PERIODIC WATERING}

\author{
M.A. Ganiev ${ }^{1}$, I.P. Kruzhilin ${ }^{1}$, K.A. Rodin ${ }^{1}$, A.B. Nevezhina ${ }^{1}$, S.D. Fomin ${ }^{2}$ \\ ${ }^{I}$ All-Russian Research Institute of Irrigated Agriculture, Volgograd \\ ${ }^{2}$ Volgograd State Agrarian University, Volgograd
}

Received 11.06.2021

Submitted 10.08.2021

\section{Summary}

The results of the joint breeding work of the All-Russian Research Institute of Rice in $2002-2015$ are presented, which boiled down to the creation of an aerobic rice variety tolerant to cultivation in unsaturated water soil with a potential yield with periodic irrigation of $6-8 \mathrm{t} /$ ha of grain, a growing season of 115 - 118 days resistant to unfavorable biotic and abiotic factors.

Abstract
Introduction. The breeding of early, mid-season and highly productive varieties of rice is an urgent task in the northern regions of rice cultivation, especially when irrigated with periodic irrigation.

Object. The breeding of the variety began with the selection of the initial material for breeding from the hybrid population of the All-Russian Research Institute of Rice at the «All-Russian Research Institute of Irrigated Agriculture» for the signs of tolerance to water shortage in the rice field, the duration of the growing season, as the main limiting factors of grain productivity in the northern zone of rice cultivation. Sample 8315 was obtained at the «All-Russian Research Institute of Rice» by the method of individual selection from a hybrid population of VNIIR $7718 \times$ VNIIR 7643 in 2008 and subsequent 